T. Vassilakopoulos

E. Zakynthinos

C. Roussos

S. Zakynthinos

\section{Respiratory muscle/circulation interaction in congestive heart failure}

Die Wechselwirkung der Atemmuskulatur und des Blutflusses bei Patienten mit manifester Herzinsuffizienz

Received: 17 May 1999

Accepted: 29 June 1999

Supported by a grant for Scientific Development in Greece (PENED 95/773/3/3001) and the Thorax Foundation

Diese Arbeit basiert auf einem Beitrag im Yearbook of Intensive Care and Engineering Medicine 1999, edited by J.-L. Vincent, Springer Verlag 1999

T. Vassilakopoulos $(\bowtie) \cdot$ E. Zakynthios

C. Roussos - S. Zahynthios

Department of Critical Care and Pulmonary Services

National and Kapodistrian University of Athens Medical School

Evangelismos Hospital

45-47 Ipsilandou Str.

Athens, Greece

E-mail: croussos@atlas.uoa.gr
Zusammenfassung Diese Arbeit befasst sich mit der Wechselwirkung der Atemmuskulatur und des Blutflusses bei Patienten mit manifester Herzinsuffizienz. Eine Dysfunktion der Atemmuskulatur, bestehend sowohl aus einer verminderten Druckerzeugungskapazität, als auch einer verminderten Ausdauer, ist bei solchen Patienten gut dokumentiert. Die Mechanismen hinter deren Entwicklung und deren potentiellen Folgen, besonders im Bereich der Dyspnoe werden diskutiert. Es besteht nicht nur Muskeldysfunktion bei diesen Patienten, unter Umständen können diese schlecht funktionierenden Muskeln den Blutfluss behindern, wie z.B. wenn der Patient von einer mechanischen Atmung entwöhnt wird. Letztlich wird die zugrundeliegende Pathophysiologie und das theoretische Modell, welche diese interessante Wechselwirkung erklärt, diskutiert.
Schlüsselwörter Atemmuskulatur Blutfluss - Herzinsuffizienz

Summary This paper reviews respiratory muscle/circulation interaction in congestive heart failure. Respiratory muscle dysfunction consisting of both reduced pressure - generating capacity and reduced endurance is well documented in these patients. The mechanisms underlying its development and the potential consequences especially in the development of dyspnea are then presented. Not only are respiratory muscles dysfunctioning in these patients, but under specific circumstances they can impede the circulation, such as during weaning from mechanical ventilation. The underlying pathophysiology and the theoretical model explaining this interesting interaction is finally discussed.

Key words Respiratory muscles circulation - congestive heart failure

\section{Introduction}

Heart failure is the pathophysiological state in which an abnormality of cardiac function is responsible for failure of the heart to pump blood at a rate commensurate with the requirements of metabolizing tissues or to do so only from elevated filling pressures (1). The clinical manifestations of heart failure, i.e. fatigue and dyspnea which limit exercise/activity tolerance are well recognized by physicians. The consequencies of heart failure on respiratory muscle function though significant are not usually appreciated. These consequencies will be the subject of the first part of the present review.

There are also circumstances where the action of the respiratory muscles poses a significant burden on the cardiovascular function of patients with heart failure. This is exemplified by congestive heart failure (CHF) patients who fail to wean, and should be rather expected since the respiratory muscles are not only functionally but also mechanically linked to the heart and 
circulation within the thorax. This cardiovascular dysfunction will be the sbuject of the second part of this review.

\section{Respiratory muscle dysfunction in patients with heart failure}

It is well established that heart failure compromises the pressure generating capacity of the respiratory muscles (2-11). The reduction in the pressure generating capacity of the inspiratory muscles has been a consistent finding in all studies addressing this issue (2-10). Hammond et al. (2) reported that the maximum inspiratory pressure $\left(\mathrm{P}_{\mathrm{I}, \max }\right)$ measured at the level of functional residual capacity (FRC) was (mean $\pm \mathrm{SD}$ ) $41 \pm 6 \mathrm{cmH}_{2} \mathrm{O}$ (with individual values as low as $20 \mathrm{cmH}_{2} \mathrm{O}$ ), representing only $40 \%$ the values of age-matched controls, and Mancini et al. (3) found a mean $P_{I, \max }$ of $46 \pm 22 \mathrm{cmH}_{2} \mathrm{O}$. Later studies have confirmed these results, although the compromise reported was less severe with average values ranging from 60 to $82 \mathrm{cmH}_{2} \mathrm{O}$ representing 65 to 80 percent of either predicted or agematched controls (4-10). The results were similar when the maximum inspiratory pressure was measured at residual volume (RV) (5). Reduced muscle strength was also documented for the diaphragm, the main inspiratory muscle $(4,10)$. The reduction in the pressure generating capacity of the expiratory muscles has been less consistent, with some studies reporting a decrease in the maximum expiratory pressure $\left(\mathrm{P}_{\mathrm{E}, \max }\right)$ at all lung volumes measured $(2,9,10)$, whereas McParland et al. (5) found a reduction in $\mathrm{P}_{\mathrm{E}, \max }$ only at total lung capacity (TLC) and not at FRC, and Nishimura et al. (6) were unable to confirm a decrease in $\mathrm{P}_{\mathrm{E} \text {,max }}$ (reporting only a tendency that was not statistically significant). All these results, obtained in stable ambulatory heart failure patients, indicate that there is an impairment in the force output of the respiratory muscles, with the inspiratory muscles suffering more severe weakness than the expiratory muscles.

The respiratory muscle dysfunction could theoretically be part of the generalized skeletal muscle dysfunction frequently observed in these patients (2), since the respiratory muscles are skeletal muscles. However, when peripheral and respiratory muscle strength was concurrently addressed in heart failure patients, the impairment in contractility of the respiratory muscles was greater $(2,11)$ (Fig. 1), and existed even in the absence of peripheral muscle dysfunction (11), which implies that the reduced respiratory muscle force output is not simply a part of a generalised skeletal muscle weakness.

It is also unlikely that the reduced $\mathrm{P}_{\mathrm{I}, \max }$ and $\mathrm{P}_{\mathrm{E}, \max }$ values recorded in these patients represent submaximal

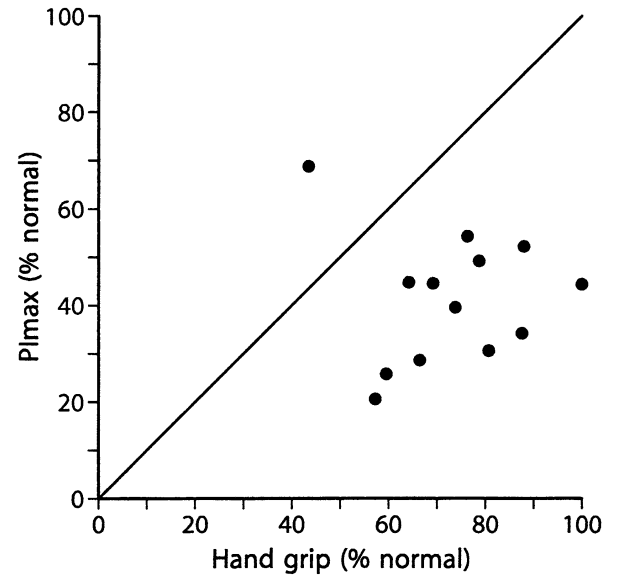

Fig. 1 Relationship between the maximum inspiratory pressure and the handgrip force expressed as $\%$ percentage of normal values. [From (2)]

or poor effort, despite the fact that both manoeuvres are volitional. Most of the studies mentioned have used sex and age matched controls and the same encouragement was given to either group during the manoeuvres. More importantly, when Mancini et al. (4) applied the twitch interpolation technique of Bellemare and Bigland-Ritchie (12) (i.e. they superimposed diaphragmatic twitches elicited by supramaximal bilateral phrenic nerve stimulation upon maximal voluntary diaphragmatic contraction) they failed to obtain increased transdiaphragmatic pressures with the superimposition of twitches. This means that most of these patients were able to maximally activate their diaphragm, and consequently the decreased pressure generating capacity recorded in heart failure patients does not result from submaximal effort, but represents true reduction in contractility. This is also supported by animal models where a reduction in twitch transdiaphragmatic pressure was recorded at all stimulation frequencies $(13,14)$.

Apart from weakness, patients with heart failure also exhibit decreased endurance of the respiratory muscles. Accordingly, Mancini et al. (4) reported that the tension time index of the diaphragm $\mathrm{TTI}_{\mathrm{di}}$ [which is the product of the mean transdiaphragmatic pressure expressed as a percentage of maximum and the duty cycle (i.e. the time spent in inspiration/total respiratory cycle duration, $\left.\mathrm{T}_{\mathrm{I}} / \mathrm{T}_{\mathrm{T}}\right)$ ] was higher in heart failure patients than in normal controls both at rest $(0.03 \pm 0.02$ vs. $0.01 \pm 0.01$, $\mathrm{p}<0.05)$ and during exercise $(0.10 \pm 0.03$ vs. $0.03 \pm 0.02$, $\mathrm{p}<0.04)$. Bellemare and Grassino (15) have shown that the value of $\mathrm{TTI}_{\mathrm{di}}$ is inversely related to the endurance time (i.e. the time that a given load can be sustained without development of fatigue). Furthermore, maximal sustainable ventilatory capacity was significantly reduced in these patients $(53 \pm 22$ liters/min vs. $90 \pm 23$ liters/min in controls, $\mathrm{p}<0.05)$. Both results indicate that 
the reserves before the appearance of fatigue are diminished in stable chronic heart failure patients. This is in concert with a canine model of chronic heart failure, where the diaphragm was found to have increased fatiguability (13). It should of course be acknowledged that diaphragmatic fatigue does not occur even during exercise in patients with stable chronic heart failure (4). However, such a possibility cannot be excluded during an exacerbation of the disease, given the fact that cardiac tamponade leading to the acute development of cardiogenic shock in dogs was able to produce diaphragmatic fatigue (16).

The aetiology of respiratory muscle dysfunction in patients with heart failure remains elusive. Dysfunction of the central respiratory controllers should be excluded, since the output of the respiratory centers (measured as the decline in airway pressure 100 milliseconds after the beginning of inspiration against an occluded airway, $\left.P_{0,1}\right)$ is increased in these patients (9). The same holds true for neural/neuromuscular transmission defects since Mancini et al. were unable to demonstrate any abnormality both are rest and at peak exercise (4). An attractive hypothesis is that underperfusion might be responsible for respiratory muscle dysfunction. The rationale behind this hypothesis is that by definition there is failure of the heart to pump blood at a rate commensurate with the requirements of metabolising tissues, and the requirements of the respiratory muscles are augmented due to the increased load of breathing, as evidenced by the high values of the tension time index (4), which is a very good approximation of the energy expenditure of the respiratory muscles (15). This is clearly the case for the most severe form of heart failure i.e. cardiogenic shock which leads to the development of respiratory muscle fatigue and force output failure in dogs (16). However, in stable chronic heart failure the evidence for the existence of respiratory muscle underperfusion is less clear. Supinski et al. (13), in a canine model of chronic heart failure induced by rapid ventricular pacing for 4-6 weeks, found that the maximum phrenic arterial flow achieved during electrically induced fatigue of the diaphragm was appreciably less than that observed in normal control dogs $\left(77.8 \pm 5.5 \mathrm{ml} \cdot \mathrm{min}^{-1} \cdot 100 \mathrm{~g}^{-1}\right.$ vs. $140 \pm 21 \mathrm{ml} \cdot \mathrm{min}^{-1}$ $\cdot 100 \mathrm{~g}^{-1}$ ). Furthermore heart failure dogs had very different phrenic flow responses to transient (1 minute) occlusion of the phrenic artery, showing less but more prolonged hyperaemia postocclusion (Fig. 2). These results suggest that there is diminised capacity for diaphragmatic muscle vasodilation and that this vascular dysfunction may be sufficient to limit blood flow. However this holds true only for high levels of force development, since under resting conditions and in response to low level repetitive contraction the diaphragmatic flows were similar in control and heart failure dogs (13), implying that the vascular dysfunction was not so severe as to limit muscle function at low levels of force development.
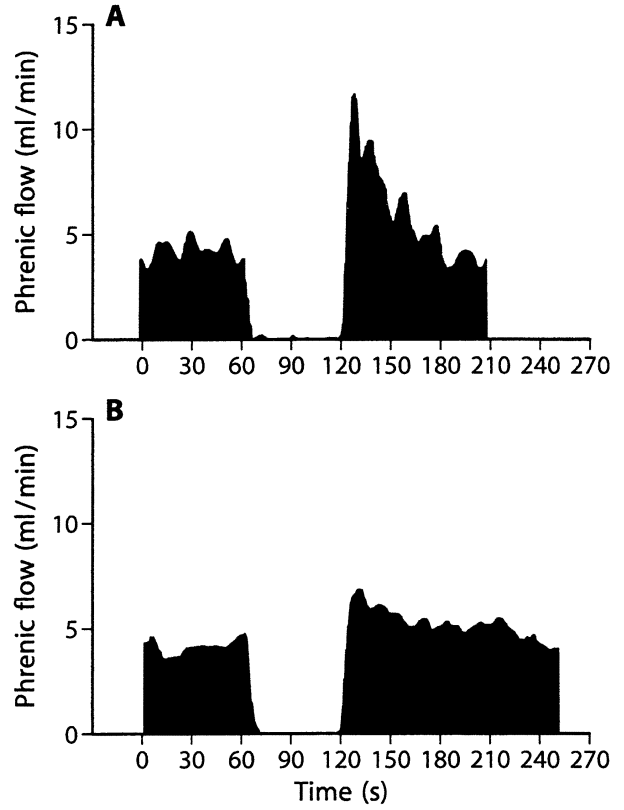

Fig. 2 Phrenic arterial flow responses to transient arterial occlusion in control (upper panel) and congestive heart failure (lower panel) dogs. The left tracings represent preocclusion flows and the right tracings postocclusion flow responses. Occlusion of the phrenic artery was transient, lasting for 1 minute. [From (13)]

The extent to which these results are applicable to humans is unknown, since measurement of diaphragmatic blood flow is as far impossible with the currently available techniques. Mancini et al. have tried to indirectly address this issue by applying the technique of near-infrared spectroscopy to detect deoxygenation of the respiratory muscles $(3,4,8)$. Near-infrared spectroscopy noninvasively detects skeletal muscle oxygenation. This technique relies on the optical properties of haemoglobin. Both oxygenated and deoxygenated haemoglobin absorb light at $800 \mathrm{~nm}$, whereas primarily deoxygenated haemoglobin absorbs light at $760 \mathrm{~nm}$. Therefore by monitoring the difference in absorption noted at these two wavelengths, it is possible to qualitatively assess changes in haemoglobin oxygenation (normalised for changes in total haemoglobin). When this technique was applied (due to technical restrains) to the serratus anterior muscle (an accessory inspiratory muscle), progressive changes consistent with deoxygenation were noted throughout exercise in heart failure patients, contrary to what happened in normal controls (3) Fig. 3. Furthermore, the response correlated significantly with the progressive increase in the tension time index. Although near infrared spectroscopy does not directly assess diaphragmatic oxygenation, it is highly likely that this is also the situation for the diaphragm which is the main muscle of inspiration and consequently its activation is more intense during exercise and therefore requires substantially greater blood flow than the serra- 

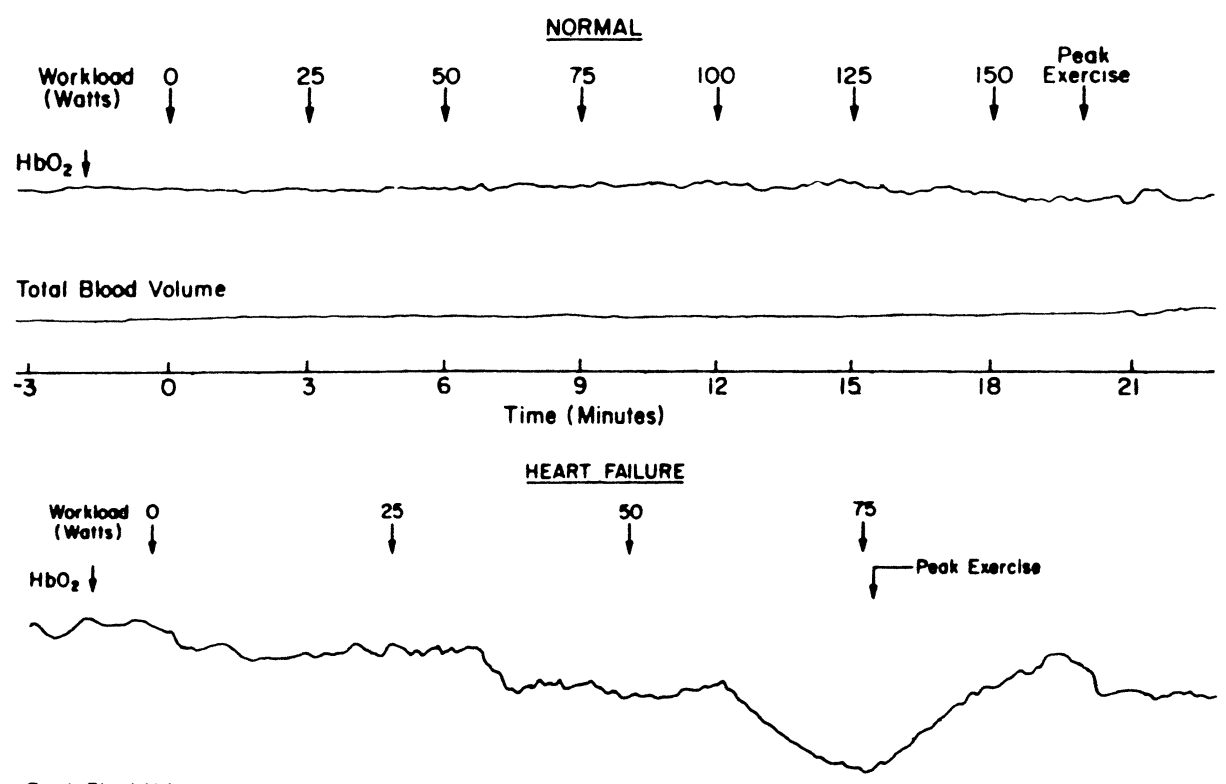

Tolal Blood Volume

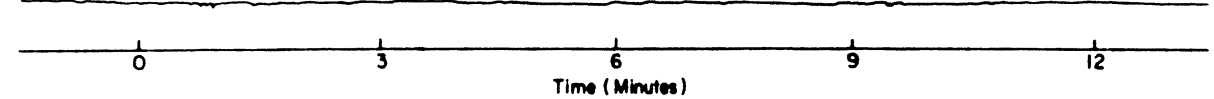

Fig. 3 Near-infrared absorption changes of the serratus anterior muscle at rest and during exercise in a normal subject and a patient with heart failure. Top curve: Difference in 760-800 nm absorption. Bottom curve: Absorption of $800 \mathrm{~nm} . \mathrm{HbO}_{2}$ : oxygenated hemoglobin. [From (4)] tus anterior. This respiratory muscle deoxygenation most probably represents increased oxygen extraction in these muscles secondary to hypoperfusion due to an inadequate cardiac output response to exercise. It should be noted however that the same investigators found only minimal accessory muscle deoxygenation (that did not reach statistical significance) during performance of the maximal sustainable ventilatory capacity manoeuvre, which implies that hypoperfusion is not significant during isolated respiratory muscle exercise despite the significant reduction of the endurance of the respiratory muscles (8). Taken together these results suggest that hypoperfusion might be present under some conditions in heart failure patients, but cannot totally account for the respiratory muscle dysfunction. This is further evidenced by the fact that cardiac transplantation only partially restored respiratory muscle endurance (17).

Malnutrition and electrolyte abnormalities which are recognized complications of congestive heart failure and can impair respiratory muscle function have been excluded as causes of respiratory muscle dysfunction in these patients (11). More likely, histological and molecular/biochemical changes within the respiratory muscles account at least in part for their dysfunction. Accordingly, Howell et al. (14) in an mini-pig animal model of chronic heart failure found atrophy of all types of diaphragmatic fibers which was more marked for type IIb fibers. Furthermore, there was a decreased proportion of type
IIa fibers and an increase in the proportion of type I fibers along with an increase of the enzymatic activity of succinate dehydrogenase (a mitochondrial enzyme involved in oxidative metabolism) in all fiber types. Stassijns et al. have also shown type I atrophy in combination with an increase in the proportion of type I fibers of the diaphragm of Syrian hamsters with congenital heart failure (18). However, Lindsay et al. (19) could not replicate the changes in fiber type prevalence or diameter in patients undergoing cardiac transplantation, although they found histological abnormalities suggesting the presence of fiber type regeneration and/or transformation (such as tubular aggregates, internalisation of nuclei, presence of cores, bizarre staining of myosin and staining for neonatal myosin). These changes were more pronounced in dilated than ischemic cardiomyopathy, which implies that the mechanism of respiratory muscle dysfunction might differ according to the aetiology of heart failure. Molecular changes have also been described in the diaphragms of both animals and humans with CHF. Accordingly, Anger et al. (20) found decreased expression of the gene coding for sarcoendoplasmatic reticulum $\mathrm{Ca}^{2+}$ adenosinetriphosphatase isoform 1 (an enzyme involved in cellular calcium regulation and contractile performance) in the diaphragm of cardiomyopathic Syrian hamsters. Furthermore, Tikunov et al. found fast-to-slow transformations of both myosin and regulatory proteins (such as $a$-tropomyosin and fast isoforms of Troponin-T) in the dia- 


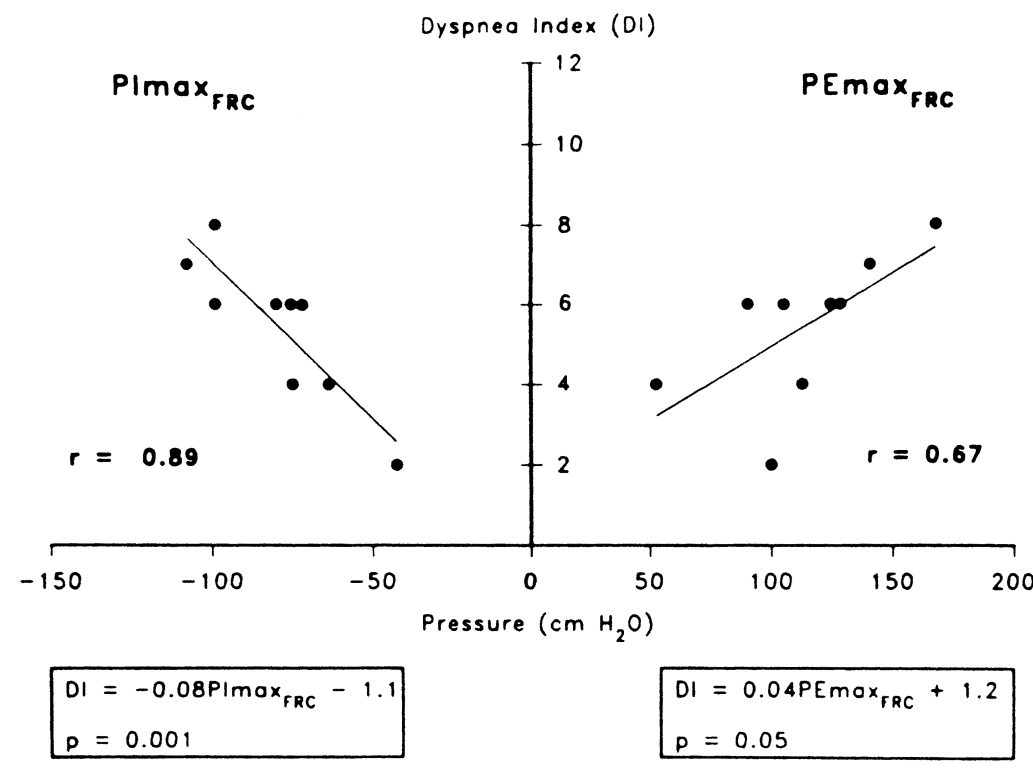

Fig. 4 Relation between inspiratory (left panel) and expiratory (right panel) muscle strength and dyspnea during daily activities in the chronic heart failure patients. Dyspnea was assessed by the baseline dyspnea index (DI). This index consists of three sections: the magnitude of the task producing dyspnea, the magnitude of the effort required to produce dyspnea, and the functional impairment occuring as a consequence of dyspnea. Each of the three sections is scored on a five-point scale from 0 to 4 based on set criteria, and the DI is the total for all three sections. Thus the DI can range from 0 to 12 in whole numbers, and the most dyspneic have the lowest score. [From (5)] phragm of patients with CHF (21). It should also be noted that both the histological and the biochemical/molecular changes of the respiratory muscles are different from the respective changes of peripheral skeletal muscles, which suggests different pathophysiologies and mandates extreme caution when results from studies in the latter are extrapolated to the respiratory muscles of $\mathrm{CHF}$ patients.

An intriguing yet inadequately studied area is the role of cytokines in the development of respiratory muscle dysfunction in these patients. Tumour necrosis factor (TNF) and interleukin-6 (IL-6) are increased especially in the most severe forms of heart failure $(22,23)$. At least in animal models tumour necrosis factor has been proved capable of compromising the contractility of the diaphragm (24). Furthermore, both TNF and IL-6 cause muscle protein wasting and cachexia. Serum insulin-like growth factor-1 (IGF-1), which causes muscle protein anabolism and myofiber hypertrophy) is decreased in cardiomyopathic hamsters (18). Interestingly, diaphragm alterations in contractile properties and histology were clearly related to the IGF-1 levels. However, the extent to which these results are applicable to humans remains as yet unknown.

The development of dyspnea is an easily understood clinical manifestation of heart failure. Its pathophysiology remains to a large extent obscure, yet respiratory muscle dysfunction most likely plays a central role. In fact, the sense of dyspnea is related to the pressure generated by the respiratory muscles relative to their maximal pres- sure-generating capacity. For a given pressure, the intensity of dyspnea is increased as the pressure-generating capacity of the respiratory muscles is reduced (25).

Various studies have established that perceived dyspnea is significantly correlated with parameters of respiratory muscle function in heart failure patients $(4,5,7$, 11). Accordingly Mancini et al. (4) have observed a significant negative correlation between both maximal inspiratory and expiratory pressure and Borg Scale recordings of dyspnea during exercise. Similar results were obtained by Hamilton et al. (7) in a much larger group of patients. Furthermore, Mc Parland et al. (5) found significant correlation between the pressure generating capacity of the respiratory muscles and the dyspnea index of daily activities (Fig. 4). It stands therefore to reason that respiratory muscle dysfunction in the face of abnormal lung mechanics (18) is the pathophysiologic derangement leading to dyspnea in these patients. The role of respiratory muscle dysfunction in the development of the other symptoms of congestive heart failure is less clear but cannot by excluded.

\section{The respiratory muscles as a cause of cardiovascular dysfunction in patients with heart failure who fail to wean}

Patients with underlying ventricular dysfunction may develop increases in pulmonary capillary wedge pres- 
sure and sometimes ultimately decreases in cardiac output upon removal from positive-pressure mechanical ventilation (26). Several factors may be responsible (27, 28). The mechanism leading to weaning failure in these patients might be considered as follows. During spontaneous or deminished support ventilation the increase in respiratory muscle work load as well as anxiety and sympathetic discharge result in an abrupt increase in oxygen and cardiac demands. The failing left ventricle then is unable to respond normally and Left Ventricular End-Diastolic Pressure (LVEDP) rises causing interstitial, peribronchiolar and alveolar edema. This reduces lung compliance, increases airway resistance and worsens ventilation-perfusion mismatching leading to hypoxemia. Energy demands of the respiratory muscles are increased while energy supplies are either diminished or not sufficiently increased (inadequate cardiac output, hypoxemia). This eventually leads to the inability to sustain spontaneous ventilation at a level adequate to achieve normocapnia and $\mathrm{PCO}_{2}$ rises. The abnormal blood gasses depress cardiac contractility and, at the same time, respiratory muscle function. This worsens blood gasses more and creates a vicious circle that may culminate in failure to wean.

The pivotal role played by the respiratory muscles in the development of left ventricular dysfunction is mediated through the effects of muscle activation on pleural and abdominal pressures. Normally spontaneous inspiration increases abdominal pressure at the same time it decreases pleural pressure due to diaphragmatic contraction and descent. The importance of the decreased pleural pressure for venous return augmentation is easily understood. Furthermore, the negative intrathoracic pressure increases the afterload of both ventricles and this, combined with the increased venous return, may lead to right ventricular distension. Because the two ventricles are constrained by a common pericardial sac and share the interventricular septum, changes in the volume of one ventricle may affect the function of the other; thus, right ventricular distension impedes the filling of the left ventricle (29). This occurs both through a generalized increase in pericardial pressure and also because of a shift of the interventricular septum toward the left. Left ventricular filling impediment increases its diastolic stiffness at the same time that its afterload is elevated due to the decreased pleural pressure. This combined effect leads to the elevation of LVEDP with the above mentioned sequence of events culminating in weaning failure.

On the contrary, the role of abdominal pressure is not usually considered significant, yet abdominal pressure surrounds the abdominal venous system through which $2 / 3$ of the venous return passes (30). Therefore, an increase in abdominal pressure could theoretically compress the abdominal veins and increase the amount of blood returning to the heart (31). In order to explain the contradictory results in the literature regarding the effects of diaphragmatic descent on venous return Takata et al. $(32,33)$ recently expanded the concept of zones of the lung to the abdominal vasculature (Fig. 5). According to their model, an increase in abdominal pressure would increase inferior vena cava (IVC) venous return when the transmural IVC pressure at the thoracic inlet $\left(\mathrm{P}_{\mathrm{IVC}}-\mathrm{Pab}\right)$ significantly exceeds the critical closing transmural pressure $(\mathrm{Pc})$ i.e.:

\section{$\mathrm{P}_{\mathrm{IVC}}-\mathrm{Pab}>\mathrm{Pc}$ (ZONE III condition)}

where $\mathrm{P}_{\mathrm{IVC}}=\mathrm{IVC}$ pressure at the level of the diaphragm, $\mathrm{Pab}=$ abdominal pressure, and $\mathrm{Pc}=$ critical closing transmural pressure. On the contrary, an increase in abdominal pressure would reduce IVC venous return when the transmural IVC pressure at the thoracic inlet is below the critical closing transmural pressure

$$
\mathrm{P}_{\mathrm{IVC}}-\mathrm{Pab}<\mathrm{Pc}(\mathrm{ZONE} \text { II condition) }
$$

because of the development of vascular waterfall. This concept was successfully tested in animal models (32, 33) and can adequately explain the results of Lemaire and co-workers (26). In this study, the hemodynamic effects of changing from positive pressure to spontaneous ventilation in 15 patients with combined COPD and coronary artery disease had been measured. Spontaneous breathing increased cardiac output and right and left ventricular filling pressures rapidly leading to respiratory failure, while weaning indices had predicted a successful weaning (Fig. 6). The increase in venous return and cardiac output was an expected finding since the decrease in pleural pressure associated with spontaneous breathing would increase venous return by lowering right atrial pressure (the downstream pressure for venous return). However, in these patients the right atrial pressure actually rose relative to atmospheric pressure despite the lower pressure surrounding the heart. The increase in venous return could have been due only to either a greater increase in the upstream pressure $(\mathrm{Pab})$ or a reduction in the resistance to venous return. Only the first probability, however, was applicable under those circumstances. Although no patient had clinical evidence of volume overload, all were subsequently forced into diuresis for one week, losing an average of $5 \mathrm{~kg}$. After that, 8 of the 15 patients were successfully weaned. These patients now had cardiac output and filling pressures during spontaneous breathing essentially unaltered from their values during mechanical ventilation. An interesting explanation for these findings is offered by the above mentioned model (34). Prior to diuresis these patients' abdomens were in ZONE III condition. When they began spontaneous breathing their mean abdominal pressure rose and led to increased venous return; this sudden increase in venous 

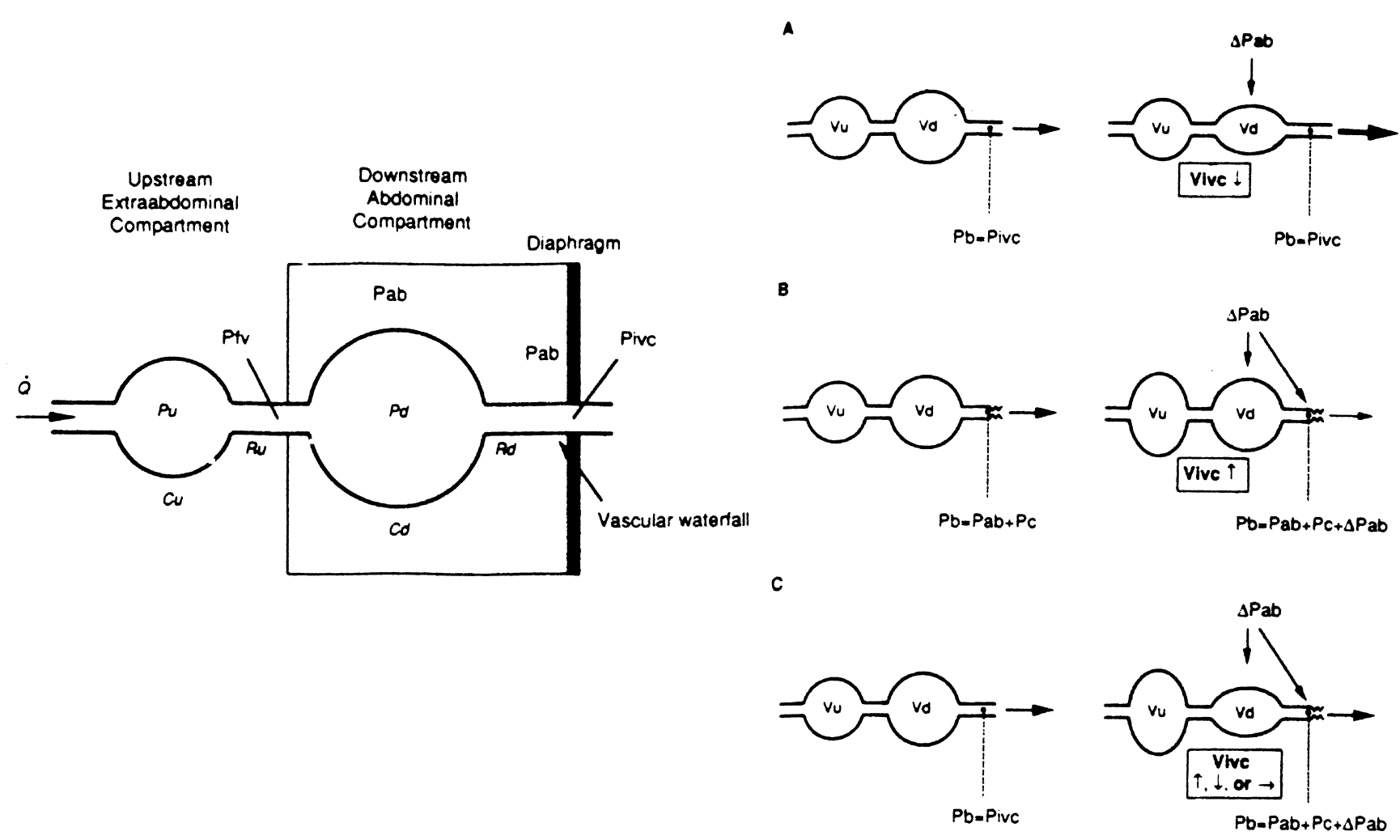

Fig. 5 Schematic illustration of model of inferior vena cava (IVC) circulation (left panel). The right panel shows changes in blood volumes in IVC circulation with an increase in the abdominal pressure (Pab) with a pure zone 3 abdomen (A), a pure zone 2 abdomen (B), and a transition from zone 3 to zone 2 abdomen $(\mathrm{C}) . \Delta \mathrm{Pab}$, step increase in Pab to achieve a new steady state. $Q=$ arterial inflow to IVC circulation, $\mathrm{Pu}=$ Pressure in upstream extra-abdominal compartment of IVC circulation, $\mathrm{Cu}=$ compliance of upstream extra-abdominal of IVC

return coupled with elevation of the left ventricular afterload caused by the lowered pleural pressure precipitated heart failure and, in turn, respiratory failure. After diuresis the abdomens of many patients were in ZONE II; increased abdominal pressure now did not increase venous return as much due to the development of vascular waterfall. Although respiratory work and left ventricular afterload initially increased as much as they had the prior week, deterioration of heart function was prevented and these patients were successfully weaned.

The increased left ventricular preload and afterload resulting from the activation of the respiratory muscles upon resumption of spontaneous breathing, may also lead to altered myocardial perfusion and ischemia (35, 36) and thus to the inability to wean sucessfully. Accordingly, Rasanen et al. (35) found electrocardiographic evidence of myocardial ischemia in 6 of their 12 patients with myocardial infarction complicated by respiratory failure upon withdrawal of ventilator sup- circulation, $\mathrm{Ru}=$ resistance between upstream extra-abdominal and downstream abdominal compartments of IVC circulation, Pfv $=$ pressure in the femoral vein, $\mathrm{Pd}=$ pressure in downstream abdominal compartment of IVC circulation, $\mathrm{Cd}=$ compliance of downstream abdominal compartment of IVC circulation, $\mathrm{Rd}=$ resistance between downstream abdominal compartment and thorax, Pivc=pressure in the inferior vena cava thoracic inlet. [Modified from (33)]

port. Furthermore, Hurford and co-workers (36) observed new regions of decreased myocardial thallium $201\left({ }^{201} \mathrm{TI}\right)$ uptake and transient left ventricular dilation in 7 of their 15 patients assessed by ${ }^{201}$ TI myocardial scintigraphy during discontinuation of mechanical ventilation. Their results suggest that the hemodynamic and ventilatory changes associated with resumption of spontaneous breathing were sufficient to increase myocardial oxygen demands (evidenced by the increased heart rate, arterial blood pressure and LV cavity size during SV) to such an extent that the available coronary oxygen supply could not meet, (probably due to coronary artherosclerosis or spasm), thus leading to ischemia. Interestingly, the authors were unable to detect any electrocardiographic changes diagnostic of myocardial ischemia, implying that electrocardiographic criteria are relatively insensitive and that myocardial ischemia should be suspected in the patient who fails to wean even in the absence of EKG changes. 
BASELINE

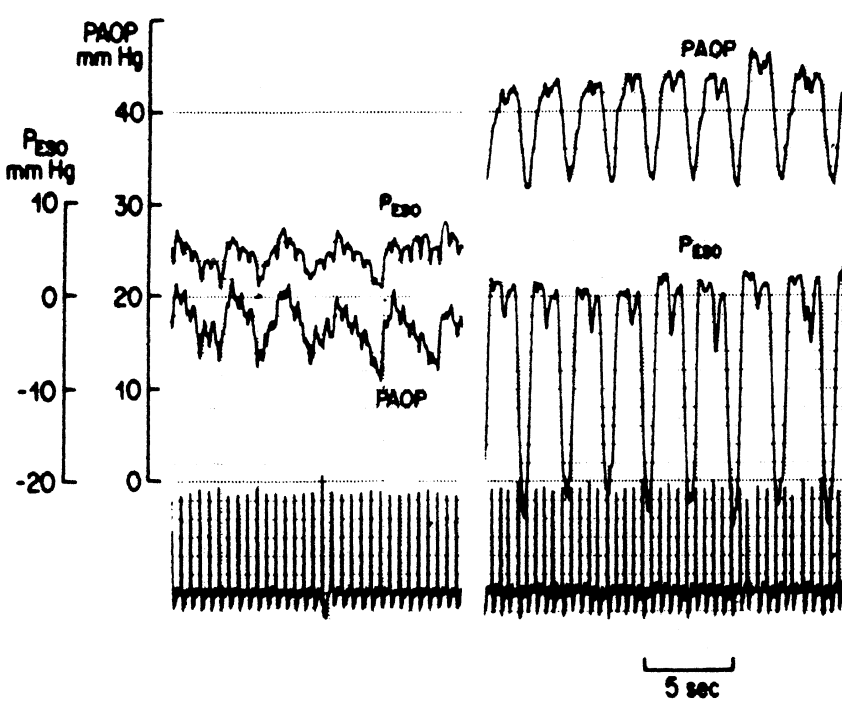

\section{Conclusion}

The respiratory muscles of patients with heart failure exhibit significant compromise of both their pressure generating capacity and of their endurance characteristics. This dysfunction is crucial for the development of dyspnea which is frequently encountered in these patients. At the same time respiratory muscle activation can precipitate cardiovascular dysfunction in heart failure patients during trials of weaning from mechanical ventilation. It thus seems that the normal beneficial interaction of the respiratory muscles and circulation is impaired or lost in CHF and this may lead to the development of dysfunction of either the respiratory muscles or the cardiovascular system.

Fig. 6 Weaning of a representative patient from mechanical ventilation (baseline) to spontaneous ventilation $\left(\mathrm{SV}_{1}\right)$. There is a progressive increase of pulmonary artery occlusion pressure (PAOP) from $14 \mathrm{mmHg}$ (baseline) to $50 \mathrm{mmHg}$ (9 min SV). The esophageal pressure is reduced during SV with marked negative inspiratory excursions. [From (26)]

\section{References}

1. Braunwald E (1992) Pathophysiology of heart failure. In: Braunwald E (ed) Heart Disease. A Textbook of Cardiovascular Medicine $4^{\text {th }}$ edition. W.B. Saunders Co, Philadelphia 393-418

2. Hammond MD, Bauer KA, Sharp JT, Rocha RD (1990) Respiratory muscle strength in congestive heart failure. Chest 98:1091-1094

3. Mancini DM, Ferraro N, Nazzaro D, Chance B, Wilson JR (1991) Respiratory muscle deoxygenation during exercise in patients with heart failure demonstrated with near-infrared spectroscopy. J Am Coll Cardiol 18:492-498

4. Mancini DM, Henson D, LaManca J, Levine S (1992) Respiratory muscle function and dyspnea in patients with chronic congestive heart failure. Circulation 86:909-918

5. McParland C, Krishnan B, Wang Y, Gallagher CG (1992) Inspiratory muscle weakness and dyspnea in chronic heart failure. Am Rev Resp Dis 146:467-472

6. Nishimura Y, Maeda H, Tanaka K, Nakamura H, Hashimoto Y, Yokoyama M (1994) Respiratory muscle strength and hemodynamics in chronic heart failure. Chest 105:355-359
7. Hamilton AL, Killian KJ, Summers E, Jones NL (1995) Muscle strength, symptom intensity, and exercise capacity in patients with cardiorespiratory disorders. Am J Respir Crit Care Med 152:20212031

8. Mancini DM, Henson D, LaManca J, Levine S (1994) Evidence of reduced respiratory muscle endurance in patients with heart failure. J Am Coll Cardiol 24:972-981

9. Ambrosino N, Opasich C, Crotti P, Cobelli F, Tavazzi L, Rampulla C (1994) Breathing pattern, ventilatory drive and respiratory muscle strength in patients with chronic heart failure. Eur Respir J 7:17-22

10. Evans SA, Watson L, Hawkins M, Cowley AJ; Johnston JDA, Kinnear WJM (1995) Respiratory muscle strength in chronic heart failure. Thorax 50:625628

11. McParland C, Resch EZ, Krishnan B, Wang Y, Cujec B, Gallagher CG (1995) Inspiratory muscle weakness in chronic heart failure: role of nutrition and electrolyte status and systemic myopathy. Am J Respir Crit Med 151:1101-1107
12. Bellemare F, Bigland Ritchie B (1984) Assessment of human diaphragm strength and activation using phrenic nerve stimulation. Respir Physiol 58:263-277

13. Supinski G, DiMarko A, Dibner-Dunlap M (1994) Alterations in diaphragm strength and fatiguability in congestive heart failure. J Appl Physiol 76 (6):2707-2713

14. Howell S, Maarek JMI, Fournier M, Sullivan K, Zhan WZ, Sieck GC (1995) Congestive heart failure: differential adaptation of the diaphragm and latissimus dorsi. J Appl Physiol 79(2):389397

15. Bellemare F, Grassino A (1982) Effects of pressure and timing of contraction on human diaphragm fatigue. J Appl Physiol 53:1190-1196

16. Aubier M, Trippenbach $\mathrm{T}$, Roussos $\mathrm{C}$ (1981) Respiratory muscle fatigue during cardiogenic shock. J Appl Physiol 51:499-508

17. Mancini DM, LaManca JJ, Donchez LJ, Levine S, Henson DJ (1995) Diminished respiratory muscle endurance persists after cardiac transplantation. Am J Cardiol 75:418-421 
18. Stassijns GS, Gayan-Ramirez G, De Leyn P, de Bock V, Dom R, Lysens R, Decramer M (1999) Effects of dilated cardiomyopathy on the diaphragm in the syrian hamster. Eur Respir J 13:391-397

19. Lindsay DC, Lovegrove CA, Dunn MJ, Bennett JG, Pepper JR, Yacoub MH, Pool-Wilson PA (1996) Histological abnormalities of muscle from limb, thorax and diaphragm in chronic heart failure. Eur Heart J 17:1239-1250

20. Anger M, Lambert F, Chemla D, Desche P, Scalbert E, Lompre AM, Lecarpentier Y (1995) Sarcoplasmatic reticulum $\mathrm{Ca}^{2+}$ pumps in heart and diaphragm of cardiomyopathic hamster: effects of perindopril. Am J Physiol 268:H1947-H1953

21. Tikunov B, Mancini D, Levine S (1996) Changes in myofibrillar protein composition of human diaphragm elicited by congestive heart failure. J Mol Cell Cardiol 28:2537-2541

22. Levine B, Kalman J, Mayer L, Fillit H, Parker M (1990) Elevated circulating levels of tumor necrosis factor in severe chronic heart failure. $\mathrm{N}$ Engl J Med 323:236-241
23. Nishigaki K, Minatoguchi S, Seishima M, Asano K, Noda T, Yasuda N, Sano $\mathrm{H}$, Kumada H, Takemura M, Noma A, Tanaka T, Watanabe S, Fujiwara $\mathrm{H}$ (1997) Plasma Fas ligand, an inducer of apoptosis, and plasma soluble Fas, an inhibitor of apoptosis, in patients with chronic congestive heart failure. $\mathrm{J}$ Am Coll Cardiol 29:1214-1220

24. Shindoh C, Hida W, Ohkawara Y, Yamauchi K, Ohno I, Takishima T, Shirato $\mathrm{K}$ (1995) TNF- $\alpha$ mRNA expression in diaphragm muscle after endotoxin administration. Am J Respir Crit Care Med 152:1690-1696

25. Kilian KJ, Gandevia SC, Summers E, Campbell EJM (1984) Effect of increased lung volume on perception of breathlessness, effort, and tension. J Appl Physiol 57:686-691

26. Lemaire F, Teboul JL, Cinotti L, Giotto G, Abrouk F, Steg G, Macquin-Mavier I, Zapol WM (1988) Acute left ventricular dysfunction during unsuccessful weaning from mechanical ventilation. Anesthesiology 69:171-179

27. Lemaire F (1993) Difficult weaning. Intensive Care Med 19:69-73

28. Richard C, Teboul J-L, Archanbaud F, Herbert J-L, Michaut P, Auzepy P (1994) Left ventricular function during weaning of patients with chronic obstructive pulmonary disease. Intensive Care Med 20:181-186
29. Biondi JW, Schulman DS, Matthay RA (1988) Effects of mechanical ventilation on right and left ventricular function. Clinics in Chest Med 9:55-74

30. Robotham JL, Becker LC (1994) The cardiovascular effects of weaning: Stratifying patient populations. Intensive Care Med 20:171-172

31. Permutt $S$ (1988) Circulatory effects of weaning from mechanical ventilation: The importance of transdiaphragmatic pressure. Anesthesiology 69:157-160

32. Takata M, Robotham JL (1992) Effects of inspiratory diaphragmatic descent on inferior vena caval venous return. J Appl. Physiol 72:597-607

33. Takata M, Wise RA, Robotham JL (1990) Effects of abdominal pressure on venous return. J Appl Physiol 69:19611972

34. Fessler HE, Permutt S (1995) Interaction between the circulatory and ventilatory pumps. In: Roussos C (ed) The Thorax, 2nd. Marcel Dekker, pp 1621-1640

35. Rasanen J, Nikki P, Heikkila J (1984) Acute myocardial infarction complicated by respiratory failure. The effects of mechanical ventilation. Chest 85:21-28

36. Hurford WE, Lynch KE, Strauss WH, Lowenstein E, Zapol WM (1991) Myocardial perfusion as assessed by thallium 201 scintigraphy during the discontinuation of mechanical ventilation in ventilator dependent patients. Anesthesiology 74:1007-1016 